\title{
La Dirección de Arte en el cine, desafíos disciplinares y pedagógicos
}

\section{Olmedo, Inés}

Resumen: Presente en el cine desde Meliés, el sustento físico de la imagen cinematográfica involucra múltiples saberes, capacidades y experiencias proyectuales y de producción que no siempre han sido acreditadas en las obras. Su abordaje académico a nivel universitario tiene sólo veinte años, y estamos hablando de una disciplina que nace junto al cine. Múltiples factores, prejuicios y aspectos ideológicos encuentran hoy una oportunidad de revertirse desde el ámbito de la formación de espectadores y de diseñadores, gracias a la necesidad de sistematizar e integrar estos conocimientos y experiencias de la práctica con los abordajes conceptuales que les dan sentido.. Se requiere entonces

Cuadernos del Centro de Estudios de Diseño y Comunicación № 67

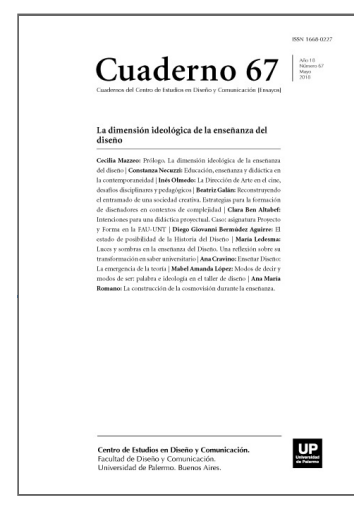

ISSN: 1668-0227

La dimensión

ideológica de la

enseñanza del diseño

Año XVIII, Mayo 2018, Buenos Aires, Argentina | 260 páginas

descargar PDF ver índice de la publicación

Ver todos los libros de la publicación

compartir en Facebook

cc) (i) Esta obra está bajo una Licencia Creative EY NC SA Commons Atribución-NoComercialCompartirlgual 4.0 Internacional elaborar contenidos y estrategias pedagógicas que respondan a la necesidad de formar diseñadores capaces de aportar valor a los proyectos audiovisuales.

Palabras clave: Cine - Diseño - Arte - espacio - imagen.

$\left(^{*}\right)$ Directora de arte, Profesora Graduada del IPA /Uruguay, artista plástica. Integra la Academia de Cine de Uruguay y el Consejo Asesor Honorario del Instituto de Cine del Uruguay. Docente de la materia en la Escuela de Cine del Uruguay, Universidad Ort y EICTV.

¿Qué hace un director de arte en el cine?

La Dirección de Arte nace junto al cine de ficción, con Georges Meliés y sus películas de temas fantásticos, que crean universos visuales propios a partir de escenografías tridimensionales, diseño de vestuario y efectos especiales. Desde el principio el rol del Director de Arte ha sido fundamental para la creación de un soporte físico capaz de ser capturado en imágenes, que represente y exprese en función de la narrativa los aspectos 
objetivos y subjetivos de la historia. En términos absolutos, la Dirección de Arte engloba todas las acciones de modificación de la apariencia de los actores, los objetos y los espacios físicos, con una intención estética funcional al proyecto audiovisual. La modificación de la apariencia, en función a la imagen final y a la cámara o el diseño de encuadre, puede suponer desde el movimiento de un objeto dentro del cuadro, en tanto esto incide en la imagen final, hasta el desarrollo de escenografías monumentales, la generación de cambios dramáticos en un actor o el diseño de objetos nuevos, no pre-existentes, que toman parte en la acción dramática. En este sentido, la Dirección de Arte no tiene sólo su territorio de trabajo en la ficción, sino también en los proyectos de no-ficción, como los documentales o el cine experimental, sea cual sea el soporte y medio de exhibición de las creaciones audiovisuales. La base física, o su representación tienen un potencial expresivo y narrativo que forma parte de la obra audiovisual, sea o no manejado conscientemente, en tanto el espectador presupone que todo lo que ve está puesto con una intencionalidad narrativa o expresiva. Este es el punto central de por qué la imagen cinematográfica no puede prescindir de una reflexión y un diseño estéticos: porque aun no habiendo un rol de Director de Arte, la imagen es interpretada como hecho artístico, producto de una intención estética, deliberada y producida en función de lo que se quiere comunicar y provocar afectivamente en el espectador. Es verdad que hay proyectos sin Director de Arte, pero la no existencia del rol dentro del equipo no significa que no haya una intención estética, o lo que es más importante, que aun prescindiendo de toda manipulación de la apariencia de los actores y los espacios, el espectador interprete erróneamente la imagen como fruto de diseño. En función de este pacto cultural, establecido entre los creadores y los espectadores, de que ninguna imagen es inocente, el rol profesional del Director de Arte se ha desarrollado y expandido en todo tipo de proyectos, desde los formatos tradicionales a los más nuevos, desde los proyectos ambiciosos a los más pequeños.

Desde el punto de vista artístico, la Dirección de Arte tiene una profunda conexión con las disciplinas tradicionales como la pintura, la arquitectura y la escultura, y a la vez con las artes escénicas, con la fotografía, con el diseño gráfico, con las manifestaciones estéticas presentes en la vida cotidiana, como los objetos de uso, la vestimenta, el mobiliario y las disciplinas proyectuales vinculadas con su diseño y producción. Desde el punto de vista estrictamente técnico, se relaciona estrechamente con los recursos de captura y post producción de imagen tanto fotográfica como generada virtualmente, con el manejo de materiales y técnicas constructivas de la arquitectura y la escenografía, y en general con todos los materiales, recursos y procedimientos de elaboración involucrados en la vida actual y en los diferentes periodos históricos, tanto en la cultura en la que se está inmerso como en las más lejanas o aun en las que sólo existen como proyección del futuro o libre juego de la imaginación.

La Dirección de Arte tiene como territorio de trabajo las tres dimensiones del espacio que Eric Rohmer (1979) señalara como constituyentes del espacio cinematográfico: el espacio pictórico, el espacio arquitectónico y el espacio fílmico. De la primera se desprende la relación directa del diseño de arte con el lenguaje pictórico, ya que enfrenta los mismos problemas formales que la pintura en la construcción del encuadre, que es la unidad básica de construcción visual del cine. La base real o virtual del hecho dramático es arquitectónica: espacios naturalistas o fantásticos donde los actores desarrollan la acción, y por lo tanto sometida a una funcionalidad de tamaños, proporciones, materiales y diseño que afecta tanto a los espacios de la escena como a aquellos que sin serlo, forman parte del contexto físico que se representa. Por último, la dimensión fílmica del espacio, es decir: la forma en que el espectador lo percibe por medio de los recursos cinematográficos del uso del tiempo, el movimiento, el montaje, el punto de vista, condiciona y posibilita que el espacio que se representa no sea necesariamente igual a los espacios físicos registrados, sino que puedan, por ejemplo, ser compuestos por dos 
o más escenarios diferentes, distantes entre sí, pero que por el montaje son percibidos como continuos y parte de una misma unidad de espacio. El movimiento de los personajes y de la cámara y el tiempo en el que una imagen se expone al espectador también determinan el tipo de exploración visual y la forma de percibir y organizar los datos del espacio presentado. Un encuadre de cámara fija, sostenido durante unos minutos permite una exploración libre y profunda de los elementos contenidos en el encuadre, convirtiéndose en un punto importante de diseño, mientras que el mismo espacio, capturado por una cámara en mano muy ágil, demandará del director de arte otro diseño muy diferente: envolvente y con puntos de interés marcados por recursos formales como el contraste de tonos, colores y formas, para comunicar de manera eficiente aquellos datos significativos para la comprensión del espacio, sus cualidades objetivas y narrativas y la forma en que es experimentado emocionalmente por el protagonista. Si bien esta diferenciación de las dimensiones pictórica, arquitectónica y fílmica es útil sólo a nivel teórico, ya que en la realidad perceptual las tres funcionan de manera indisoluble, en este caso son útiles para analizar las diferentes exigencias de diseño (imagen bidimensional, espacio tridimensional transitable y no transitable, incidencia del tiempo, el movimiento y el montaje en el acto perceptual) involucradas en la construcción de un mismo espacio.

El rol de Director de Arte implica entonces algo muy diferente a la construcción de decorados, a la "decoración" de los espacios, al diseño de un vestuario o el maquillaje que se aplica a un actor, si bien todas estas actividades son parte de los recursos que el director de arte debe brindar al proyecto audiovisual. El rol involucra, más allá de la concreción práctica, la participación activa del Director de Arte en la construcción de sentido de un proyecto a través de la propuesta de una identidad visual que no es la mera transcripción de lo "real", sino siempre un proceso creador que involucra elegir, seleccionar, estilizar y modificar lo dado por el mundo real, en función de un planteo estético funcional al proyecto. Por otro lado, la Dirección de Arte tiene como objeto la concreción material, concreta, de esa base física en función de la producción del rodaje, es decir, dentro del tiempo y el presupuesto de la producción. Las decisiones relacionadas con el uso de los recursos tiempo, dinero y trabajo caen dentro de las responsabilidades del rol, que gestiona los recursos disponibles dentro del contexto concreto donde se concreta el proyecto.

Las áreas de trabajo de la Dirección de Arte se dividen en dos: las relativas al personaje y las relativas a los espacios. Las primeras generan un área llamada de Vestuario y Maquillaje, donde se reúnen profesionales y técnicos dedicados al diseño y producción de maquillaje, vestuario y accesorios de los personajes, internos al equipo y proveedores externos, que trabajan desde la pre producción al rodaje y su cierre administrativo. El área de espacios, Ilamada tradicionalmente "Dirección de Arte" en la industria norteamericana a su vez se subdivide en dos áreas: la de escenografía y la de ambientación, cada una trabajando coordinadamente. La supervisión general del departamento está a cargo de un "Production Designer" en la terminología anglosajona, sin correspondiente traducción al español.

Los equipos desarrollados en el cine industrial son numerosos, con funciones muy delimitadas para cada miembro del departamento de arte. Es un formato costoso, a veces pesado, pero que tiene la ventaja de no sobrecargar de tareas a ningún puesto, es decir, es sustentable. Los técnicos de los países desarrollados cuentan con protecciones sociales específicas, que aun en el ejercicio libre de la profesión los protegen cuando están desempleados o se obliga a integrar equipos con técnicos de edad madura y equidad en género. En los equipos del cine independiente, en especial de nuestros países, una sola persona en el equipo asume varios roles, ya que necesariamente todos deben cumplirse, lo que obviamente abarata los proyectos, pero también los hace poco sustentables en términos de salud, volviéndose cuando se hace regular la producción, en un sistema 
sólo apto para los más jóvenes. Esto vuelve a nuestros equipos menos eficientes, ya que la experiencia de los miembros mayores se pierde.

Parece importante pensar para qué mundo del trabajo estamos educando a estos artistas - cineastas - técnicos, cuáles son sus expectativas posibles de llevar adelante sus proyectos en un entorno profesional, sean estos de carácter visual-artístico, de autor u orientados al gran público. En cualquiera de las hipótesis que podemos manejar hoy, aun la de la práctica artística no rentada ni rentable, en cualquiera de los formatos conocidos o por inventar, la concentración de energías y esfuerzos en un campo concreto de actividad es más gratificante y productiva en términos de calidad que el ejercicio irregular de las prácticas artísticas o técnicas. Sin regularidad no hay profundización de la experiencia ni actualización posibles. Para aquellos que quieran apostar a desarrollarse en el campo audiovisual como partícipes activos es importante que el medio académico acepte e integre, profesionales en ejercicio que trabajan en medios diferentes, en formatos de producción de una amplia gama y que están insertos en el mundo real de la producción audiovisual. En ese sentido lo académico puede operar como un factor de cambio en las actuales condiciones del mundo del trabajo audiovisual, que no son óptimas ni responden con arreglo a un medio profesionalizado y de alta ocupación, generando discusión sobre las relaciones en el mundo del trabajo y sobre todo, fomentando las conductas éticas, colaborativas y responsables.

La constitución de la disciplina y las barreras para su ingreso al contexto académico

La Dirección de arte nace como una aplicación directa de las técnicas y procedimientos de diseño del teatro, de donde provenían cineastas fundantes como Meliés. En un principio, cuando aún no se había desarrollado el lenguaje propio del cine, los primeros decorados fueron telones pintados, replicando el estilo de los usados en el teatro y el music hall. El cine mismo era considerado un entretenimiento del mismo nivel que las ferias y se sospechaba que sería un negocio de corto alcance. En paralelo a estas primeras aventuras destinadas al público, las cámaras comenzaron a venderse a precios relativamente accesibles en todo el mundo, por lo que es casi paralelo el surgimiento del cine de ficción con el cine amateur familiar, y muchas veces, como en el caso de la cineasta Alice Guy, el paso entre la producción de aficionados y la y la producción con fines comerciales fue muy breve. Es Alice Guy la primera en fundar una productora con el esquema que hoy seguimos usando, y también la primera en ir a la ruina.

El panorama de las llamadas "bellas artes" entraba en crisis con los movimientos renovadores de los impresionistas, la fotografía, el diseño industrial y la gráfica, configurando un panorama propicio para el trabajo interdisciplinario entre pintores, arquitectos, escultores y el teatro, el ballet y también el cine. En los primeros años del siglo XX surgen estos cruces que atraviesan todo el siglo, marcando al cine con la impronta del arte contemporáneo de diferentes maneras.

En Alemania, por ejemplo, se da el caso de experiencias estéticas marcadas fuertemente por el expresionismo, como es el caso del Gabinete del Dr. Caligari (Robert Wiene, 1920), en Francia las experiencias cinematográficas de Jean Cocteau con La sangre de un poeta (1930) y el Ballet Mecánico de Fernad Leger (1924), o la colaboración artística entre Dalí y Buñuel en Un perro andaluz (1929). Es en este punto, rozando los años 20 , que comienza la separación entre cine de entretenimiento y cine como arte. Son los años donde la industria comienza a establecer un sistema de producción basado en resultados económicos, y las apuestas se redoblan para obtener la mayor cantidad posible de utilidades. Una de esas apuestas tiene que ver con la 
Dirección de Arte: la grandiosidad o lujo de los decorados y vestuarios de las películas comienza a ser un elemento importante, que se subraya y es parte de la publicidad de una película. Es el caso por ejemplo de Intolerancia, de Griffith (1916), como lo había sido en Italia con Cabiria (1914). Estas enormes construcciones escenográficas requirieron el trabajo de arquitectos, artesanos y artistas que venían del terreno de la construcción real o que adaptaron sus técnicas pictóricas a la producción de matte paintings, los fondos pintados que completaban las imágenes obtenidas por captura fotográfica de escenarios reales. La película de los Hermanos Taviani, Good morning, Babylonia retrata esta época pionera a través de la historia de dos hermanos italianos, constructores de iglesias, que llegan a Hollywood a construir estos decorados grandiosos y efímeros.

El cine en Rusia se desarrolla con dos vertientes artísticas principales: la fundada por Eisesten, con una visualidad de exquisita composición y fuerza expresiva, que marcará una tradición de cine plásticamente valioso en los países de Europa oriental en el cine de ficción. Por otro lado, se inaugura una vertiente documental con Verztog, que si bien se interrumpe con el estalinismo, sienta las bases de un estilo casi experimental tanto desde la cámara como por los criterios de montaje. La influencia de este cine es importante en el desarrollo de los cineastas latinoamericanos, por el acceso regular a sus obras fuera del marco de la distribución comercial del cine norteamericano. Las cinematecas y clubes de cinearte que surgen en la segunda mitad del S. XX tienen un rol fundamental en la difusión de estas cinematografías no centrales y ejercen una suerte de magisterio informal, generalmente apoyado por la crítica y la labor teorizante de sus miembros. El caso más importante es el francés, con la publicación Cahiers du Cinema.

La tensión entre las aspiraciones artísticas de los directores de arte del cine anterior a la instalación del sistema industrial y los productores comienza muy pronto en la historia del cine: en 1922 a la directora de arte Natacha Rambova se le prohíbe por contrato la entrada a los estudios donde filmara su marido. Rambova había producido ya el arte de tres películas para C.B de Mille, Camille, y Salomé en 1922, cuando diseñó la imagen exótica de Rodolfo Valentino, logrando su imposición como el primer ícono sexual de la pantalla. Rambova se retira en 1925, cuando ya el cine de industria había adoptado definitivamente los modelos de la producción y el esquema vertical que aun hoy lo rigen. Los resultados económicos esperados por los empresarios llevaron a la producción a someterse a los mismos principios que habían sido probados en el sistema industrial y en el ejército: un sistema jerárquico donde la producción se realiza en serie, sin control artístico de los directores, y donde cada actor, cineasta y artista debe someterse a un régimen de trabajo dentro de las pautas de eficiencia y rentabilidad definidas por la productora. Así se organizan en los estudios más importantes los departamentos de arte, con sectores bien diferenciados y una distribución rígida de las tareas, donde los directores de arte quedan bajo la supervisión de un "supervisor artístico", que imprime a todas las producciones un sello estético homogeneizante del estudio y asegura un standard de "calidad" visual al estudio. La necesidad de control total sobre los factores de la producción favorece el desarrollo de las escenografías de estudio sobre el uso de locaciones reales o de los traslados de equipos numerosos a otros países o regiones.

En los años ‘30 y ‘40, en la llamada "Época Dorada” de Hollywood coinciden la organización de estos gigantescos departamentos de diseño y realización de escenografía, vestuario y atrezzo con la implementación de depósitos que permitieran usar una y otra vez cada traje, silla y pavimento escenográfico. Así también las escenografías de estudio, tanto interiores como exteriores se utilizan varias veces, en ocasiones con mínimas variantes y otras en dos turnos, como parte de una estrategia de filmar en los mismos decorados una versión en inglés y otra en español, con diferentes actores, la misma película. Se desarrollan en esta época los archivos y bibliotecas, que guardan la documentación relevada para cada proyecto: libros, fotografías, investigación 
histórica, muestras y bocetos. Un director de arte no tiene el control total sobre su diseño, ni puede participar por ejemplo en el dibujo de los planos ni realizar por él mismo una pieza de utilería, y pasan de un proyecto a otro por asignación directa de la producción. De esta etapa es un símbolo Cedric Gibbons, el director de arte supervisor de la MGM, quien trabajó más de treinta años en el mismo estudio imprimiendo a las producciones el estilo particular de diseño que se convirtió en el "sello" MGM en esas décadas: estilización de las formas tanto en los proyectos de época como en los contemporáneos, decorados en colores claros y con una aspiración a dictar cátedra de elegancia al público. Los vestuaristas de esa etapa son funcionales al sistema "de stars" creado por la misma industria: trabajan en función de resaltar la belleza de los actores y disimular defectos, adaptando modas y estilos históricos a los patrones estéticos al uso y no a las necesidades de la narración. La prensa replica cada decorado y vestuario, convirtiendo al cine en una lección de "buen gusto" que puede comprarse o copiarse al bajo costo de una entrada. Luego, las tiendas destinadas al consumo masivo repetirán el modelo de tal estrella y venderán cientos de miles de réplicas de diferente calidad y precio en todo el país. El cine se reveló como un poderoso formador del gusto en cuanto a las formas de la casa habitación, aun sin tenerlo como objetivo: los baños se volvieron por primera vez objetos de diseño gracias al desarrollo de escenas donde las protagonistas tomaban largos baños. Lo que en realidad era un recurso para mostrar parcialmente a una actriz sin ropa se volvió un modelo a copiar, valorizando un área de la vivienda que tradicionalmente había sido resuelta sin ningún énfasis ni cuidado especial. Lo mismo sucedió con las lámparas de media altura, que fueron usadas por la ambientadora Laura Heron como recurso para proveer a la fotografía de puntos de luz que justificaran la iluminación de un interior. Las lámparas que se usaban en ese momento eran las de pie y las del tipo veladoras, de pequeña altura, pero la aparición en pantalla de esas lámparas de mesa, con una altura entre cuarenta y cincuenta centímetros, pronto fue un pedido del mismo público a los comerciantes, ya que lo habían visto en el cine.

Mientras en EEUU se desarrolla una industria del cine pujante y próspera, en Europa los años treinta prefiguran la segunda guerra mundial, y especialmente desde Alemania comienza una ola migratoria de cineastas, escritores, actores y también directores de arte que huyen de la persecución que comienza a instalarse por razones de raza o ideológicas. Varios de los dueños de los estudios eran alemanes de origen y mantenían vínculos con el cine europeo signados por la admiración de sus logros culturales, por lo que esta corriente se vio favorecida por contratos y condiciones de trabajo estimulantes desde principios de los años treinta. Los directores de arte que llegaban venían no sólo con una sólida formación artística en arquitectura o pintura, y con experiencias de trabajo en el cine sino también con el contacto vivo de las corrientes renovadoras del arte europeo, en especial la Bahaus y el expresionismo. El desarrollo del llamado "Cine Negro" debe mucho su estética a la incorporación de estos aportes, que también influyeron en el tratamiento de los espacios históricos en el cine y en la introducción de elementos expresivos dentro del espacio, que ya no se considera sólo como un decorado donde jugar las escenas, sino un elemento capaz de hacer un contrapunto irónico o profundizar significados. Un caso paradigmático de esta influencia, es el diseño de arte de Citizen Kane, de Orson Welles (1940), donde se da una circunstancia de producción extremadamente favorable a la innovación estética: un director joven e inexperiente, rodeado de un equipo experiente y motivado, al que se da carta blanca en recursos, libertad y tiempos de pre-producción para investigar y proponer. El director de arte fue Van Nest Polglase, quien como el director de fotografía, Gregg Toland, tenían ya carreras sólidas, pero la oportunidad de experimentar los llevó a innovar en un sentido que la producción de la época consideraba radical: el uso de teleobjetivos y de efectos especiales, para lograr profundidad de campo y el foco en los varios niveles del espacio, o los encuadres contrapicados, incluso posicionando la cámara en un agujero bajo el nivel del piso, y 
descubriendo un elemento que no aparecía usualmente en las imágenes de la época: los techos. El diseño de arte de Citizen Kane para un espectador de 1940 era una especie de catálogo de las peores características del denostado estilo victoriano de principios de siglo, por lo que la acumulación de piezas de orígenes y estilos diferentes, tenía un peso afectivo mucho más fuerte en ese momento que ahora, por el rechazo al eclecticismo historicista y al "horror al vacío" que había permitido en la época el triunfo de otras estéticas, más despojadas y "minimalistas". El uso del estilo Gótico tiene también un peso diferente para un espectador de la época que para uno contemporáneo: era el estilo usado en el género de terror y de lo que Antonio Ramírez llama de "la ciencia siniestra". Pero también hay un uso deliberado de recursos universales como los espacios desmesurados, fuera de escala para la arquitectura doméstica de Xanadú, o el uso de elementos decorativos como los espejos que crean una perspectiva abisal de la imagen solitaria del personaje. Es difícil, tratándose de un cineasta como Orson Welles que compartiera el crédito por estos conceptos visuales, pero es bastante razonable suponer que son aportes de su director de fotografía y de arte el haber usado en un sentido diferente los motivos visuales ya establecidos por el cine negro, el cine de terror y las innovaciones técnicas que permitieron establecer nuevos puntos de vista y sacarles partido expresivo.Un año antes, un productor agradecido si había hecho un reconocimiento explícito a la tarea de Cameroon Menzies, pidiendo se creara el crédito de Production Designer para subrayar el fundamental papel que había desarrollado en el proceso de trabajo de Lo que el viento se llevó (1939). La producción había sido accidentada, con varios cambios de director, que podrían haber provocado el fracaso del proyecto. El diseño integral de Cameroon Menzies, quien estuvo siempre al frente de la Dirección de Arte, logró convertirse en la referencia firme de los objetivos de narración. Son testimonios de su trabajo la serie de acuarelas, que funcionan como lo que hoy se llama concepts: imágenes que representan lo que ha de verse como resultado final en el cuadro y que funcionan como guía gráfica de apoyo al diseño de las tomas a realizar. La capacidad de un director de arte para conceptualizar en términos fílmicos se unió, en Menzies con el diseño particular de soluciones de producción, como quemar los decorados de Intolerancia, que estaban en pie desde 1916, para filmar el incendio de Atlanta.

La edad de oro del cine de estudios entra en crisis durante la Segunda Guerra mundial, cuando los esfuerzos patrióticos por racionalizar el uso de materiales inciden en los recursos asignados a la construcción de escenografías. Pero el gran golpe vendría realmente de la mano de un cine urgente, nacido en Italia en 1943 con Roma, ciudad abierta, filmada por Rosellini en medio de infinitas limitaciones materiales, prescindiendo de decorados y con actores no profesionales. El cine del neorrealismo italiano abre el camino a las cinematografías emergentes latinoamericanas, y también golpea al cine norteamericano, donde el mundo glamoroso de las comedias de teléfono blanco dejan de tener sentido y dejan paso a películas donde el desencanto y la sospecha piden un lenguaje visual más despojado de artificios y lujos de producción. El cine de autor se abre camino, de la mano de algunos cineastas que prescinden de la parafernalia de los grandes estudios, de los equipos costosos y con técnicos especializados en cada área.

En Latinoamérica el cine tuvo un primer auge de producción en las primeras décadas del SXX que se corta abruptamente con la aparición del cine sonoro, que exigía equipos y procedimientos costosos y fuera del alcance de los cineastas emergentes. Hay un cine fundacional del que sabemos poco en cuanto a términos de producción de arte, en parte porque muchas de las películas rodadas desaparecieron en incendios (el celuloide era un material altamente inflamable y los incendios eran frecuentes) o fueron recicladas como peines y peinetas, entre 1920 y 1940. De esta primera etapa suponemos que los mismos escenógrafos teatrales fueron los constructores de decorados, y el rol de Director de Arte no aparece identificado como tal. En los años treinta 
hay un movimiento importante de producción, especialmente en México, donde se filma según los métodos de producción norteamericanos y aparecen algunos escenógrafos acreditados. En Argentina pasa otro tanto, con una producción de comedias costumbristas y melodramas de corte naturalista, con escenografías de corte teatral que generalmente se limitan a tres paredes. En nuestro país hay un intento en los años treinta de producir cine nacional, pero las experiencias son aisladas y el diseño de escenografía queda en manos también de escenógrafos de teatro, mientras que el vestuario no aparece como crédito técnico. Los años sesenta y setenta serán los de la fundación del llamado "Nuevo Cine Latinoamericano", de la mano de cineastas como Glauber Rocha, que filman en escenarios naturales, con equipos técnicos pequeños y donde el acento está puesto en el valor documental de la imagen. En Cuba en 1968 Tomás Gutiérrez Alea filma Memorias del Subdesarrollo, que por ser una reconstrucción del pasado reciente (la historia transcurre en 1961) se rodó en forma documental en los exteriores, sin intervenir, y sí tiene un obvio trabajo de ambientación en la casa del protagonista. Sin embargo, el director de arte no fue acreditado, ya que en la categorización del trabajo en cine, no se había considerado este rol.

El cine europeo posterior a estos años de ruptura con los esquemas productivos hegemó- nicos del cine de industria es un cine que no abandona los temas artísticos (Passion, de Godard), ni la posibilidad de generar universos de fantasía que requieren poner en juego recursos de diseño y producción muy significativos (Fellini) o la reconstrucción histórica (Antonioni, Passolini). El cine norteamericano hace lugar a producciones filmadas fuera de estudio y hasta del país, adoptando lenguajes estéticos renovadores y más experimentales (Sunset Boulevard, Billy Wilder, 1950), con referencias artísticas muy directas, como en el caso Hichtcock-Hooper. El cine que se produce en Europa Oriental y en los países nórdicos toma identidad visual propia, y otro tanto sucede con los cineastas orientales, como Ozu, que hacen de su tradición pictórica el eje de identidad también de las formas de contar el espacio. No asistimos a un quiebre entonces de la tradición de diseño de arte, pero sí a un repliegue de proporciones, a una invisibilización de sus creadores, que ya no tienen el rol en los medios de las décadas anteriores. Los estudios tienden a reducir el personal estable y nacen, junto con las nuevas productoras independientes, los profesionales free lance, que no están atados por contrato con ningún estudio.

En las décadas de los sesenta y setenta se operan entonces varios cambios importantes que tienen incidencia en la forma en que se considera el rol del Director de Arte dentro de los equipos de producción y los proyectos cinematográficos. El primer cambio tiene relación directa con la sustitución de un sistema centrado en la figura del Productor, por la reivindicación de la libertad creativa y la importancia del Director como autor. Como consecuencia directa, se invisibilizan los aportes creativos del equipo, concentrándose los rasgos de estilo visual en el director. El segundo cambio se relaciona con la ruptura del sistema de producción de los grandes estudios, que si bien sobrevive hasta el presente, se debilita en las infraestructuras destinadas a la producción en serie como patrimonio exclusivo de un estudio: los depósitos y archivos comienzan a alquilar y se convierten en proveedores de proyectos externos a las empresas, se desarman los talleres de arquitectura destinados al diseño de escenografías y los puestos técnicos de diseño y realización se convierten en profesionales independientes o empresas proveedoras de realización. Es importante entender que aun debilitada, descentralizada y con un funcionamiento más empresarial que el modelo fabril anterior, la cultura de diseño y realización de escenografías y vestuarios configura una tradición que no se pierde, sino que sobrevive dentro de nuevos parámetros.

En cuanto a la incidencia del diseño cinematográfico en la construcción de una visualidad contemporánea, su influencia sigue siendo significativa, aunque no ya desde un discurso homogéneo y vertical, con pretensiones 
didácticas sobre el "buen gusto" y "el estilo de vida", sino con mayor apertura a las nuevas manifestaciones estéticas y a la diversidad de discursos visuales. En este sentido, el cine sigue siendo un vehículo privilegiado para poner en contacto a las nuevas tendencias estéticas con el gran público, a veces en una forma crítica y otras como aceptación de una realidad emergente. El cine impulsó estilos como el Art Decó, si bien lo hizo identificándolo con la vida moderna, los personajes superficiales y los conflictos existenciales de una clase pudiente, ajena a los problemas sociales. El cine también dio su mirada sobre la arquitectura racionalista, tomando partido a favor en películas como El manantial (1949), donde el protagonista es un joven arquitecto tras el sueño de construir un rascacielos. Indirectamente aportó a difundir el "estilo internacional", derivado de la Bauhaus y con sede en Chicago desde los años 30, así como la difusión masiva de pintores como Toulousse Lautrec (1952) o Van Gogh (1959) a partir de las biopics de John Houston, Vincent Minelli y Geroge Cuckor.

Más tarde, comenzando los años 70, será el momento de integrar la contracultura juvenil y sus innovaciones estéticas, en consonancia con el pop art y las nuevas corrientes literarias, como es el caso de Blow Up (1966, Antonioni), en una película basada en un cuento de Cortázar y que plantea el conflicto de lo aparente y la realidad a partir de la figura de su protagonista, un fotógrafo de moda. Lo que se estaba preparando, y que surge en la esté- tica de La Naranja Mecánica o de Odisea 2001, de Stanley Kubrick, es la posmodernidad: esa claudicación frente a los ideales absolutos de renovación o búsqueda de nuevas formas, que en términos estéticos se traduce en una continua revisión de los modelos estéticos del pasado, en la aceptación sin crítica de lo kitch, que se coloca al mismo nivel de lo canónico, en la sospecha continua de la impostura. Si bien el cine, como dice Ranciere:

La especificidad del cine es haber podido desarrollarse bajo una forma no experimental, a gran escala, aprovechando su estatus de entretenimiento. Si el cine ha podido negociar ciertas transacciones poéticas entre regímenes de narración y descripción diferentes es debido a que ha podido negociar tranquilamente la relación entre entretenimiento y arte, porque nunca ha sufrido el peso de demandas artísticas, porque ha estado encerrado en un espacio de diversión de masas, ha escapado de la urgencia política que ha conducido a la literatura, a la pintura, al teatro o a la música hasta respuestas globales. Incluso el imperativo industrial que obliga a los directores a rodar guiones impuestos, bajo reglas determinadas, ha otorgado al cine una especie de abrigo para definir una "modernidad tranquila"...

"El destino del cine como arte" (Entrevista a Jacques Ranciere). Declaraciones a su amiga Emmanuel Burdeau y al editor de "Cahiers du Cinéma" JeaMichel Frodon (1/12/2004) publicada en la edición 598 de la revista francesa.

Dentro de esta "modernidad tranquila" se encuentran las obras que citábamos de Stanley Kubrick, La Naranja Mecánica (1971) y Odisea 2001(1968), a la que agregaría Barry Lyndon (1975), que cada una a su manera ofrece una forma nueva de plantear la identidad visual de una pesadilla prospectiva, de un viaje metafísico hacia el futuro minado por la inteligencia artificial, y del pasado. En Odisea 2001 el diseño de arte mezcla elementos contemporáneos de avanzada con un final donde el estilo de los muebles y la arquitectura es una gélida versión del neoclásico del S.XVIII, y el personaje más interesante es sin duda Hal, la computadora que pide clemencia y muere cantando una canción infantil del S XIX. En La Naranja Mecánica la mezcla de estilos es mucho más evidente y vertiginosa: desde el vestuario de los pandilleros que mezcla elementos del vestuario masculino tradicional inglés de la época victoriana con mamelucos, hasta el paseo por un pop art deteriorado ( la casa del protagonista), ambientes de diseño vanguardista (la casa del escritor y su mujer), otros donde las obras de 
David Hockney hacen de contrapunto a la escena de la muerte de una mujer atacada con un pene gigante, o el teatro barroco que es el escenario de una violación a la actriz. A partir de Kubrick, el futuro deja de ser un sueño de progresión del diseño, como en las películas de James Bond diseñadas por Ken Adams, para convertirse en un territorio de hibridaciones y citas cruzadas al pasado. Pero es imposible diseñar el futuro sin tener en cuenta algunas obras como Metrópolis de Fritz Lang, o a Kubrick, porque el diseño en el cine instala imaginarios que adquieren el valor de una realidad vivida y experimentada, así sea exclusivamente en la pantalla. También en este territorio de los imaginarios, es importante el aporte de Kubrick a las formas de representar el pasado con su película Barry Lyndon. En el cine anterior, el pasado histórico es una referencia siempre estilizada y muchas veces estrictamente en función del destaque de una estrella. El rigor histórico de cómo lucirían ciertos vestuarios o espacios cede siempre a la tentación de estilizar e incluso idealizar el aspecto real, por no hablar de la diferencia de percepción que implica la iluminación de un interior con poderosas luces cenitales respecto a la experiencia de un habitante de un espacio similar iluminado exclusivamente por luz de velas. Lo interesante es que esos espacios, y recursos como la proliferación de espejos y cristales tallados tenían sentido en el aprovechamiento máximo de las fuentes de luz y su multiplicación, pero bajo una iluminación más generosa, se convierten en objetos absolutamente diferentes. Lo que Kubrick hizo por las futuras representaciones de los tiempos históricos lejanos fue iluminar las escenas con el mismo tipo de iluminación de la época, incluso reconstruyendo las cantidades razonables según la clase social de los protagonistas. También en pos de la verosimilitud fue usar elementos reales (vasos de vidrio grueso para la casa campesina) y materiales originales (las telas de los vestuarios fueron compradas a tejedurías que trabajaban con procedimientos y materiales incambiados desde el S. XVIII). Este naturalismo, documentado y fiel a la pintura de la época que reconstruye, tanto en el sustento material de la imagen como en la iluminación y hasta el tipo de encuadres, constituye una ruptura y una suerte de obligación para los proyectos que le siguen.

El cine industrial parece tener una perpetua melancolía por la era dorada, que se manifiesta en proyectos ambiciosos, donde la publicidad de expectativa subraya el lujo visual de la obra, o incluso se desarrollan campañas de venta de réplicas de elementos de vestuario o ambientación usados en la película, que aspiran a convertirse en "tendencia". Los tiempos parecen no haber cambiado cuando cincuenta años después de la venta masiva de un modelo usado por Betty Grable en 1939, en, el vestido usado por Demi Moore en Propuesta indecente (1993.), que alcanzó a vender más de un millón de réplicas. Esas cifras no registran todos los casos de copias no comercializadas, que multiplicarían la cifra varias veces. Es el caso interesante de una película mediocre, como El Gran Gatsby (Baz Luhrmann, 2013), una remake de un éxito de 1974, pero con el uso intensivo de recursos de post producción, que la convierten visualmente en un despliegue de decorados, vestuarios y efectos manieristas que terminan sepultando la historia. Lo más interesante está fuera de la película: es la campaña que intenta poner de moda la "época Gatsby", y el uso de recursos en internet como la aparición de publicidad de ventas de réplicas de piezas de decoración de la película asociadas en el mail con búsquedas similares en Google. Pero las viejas técnicas de difusión no sólo toman formatos nuevos para llegar al público y provocar el consumo. El "merchaindasing" de las películas se convierte para estos proyectos en un nuevo territorio no sólo de diseño asociado, sino que evoluciona e involucra aspectos narrativos: ya la historia y los personajes no existen sólo en el formato película, sino que se extienden en múltiples plataformas, donde se desarrollan historias independientes, que inciden en la trama central y sin las cuales no puede entenderse la obra en su totalidad, además de aparecer en objetos de uso o coleccionables que se comercializan mediante campañas millonarias. 
A pesar de la separación entre cine industrial, cine independiente y cine experimental que marcan las últimas cuatro décadas, la realidad es que los artistas, profesionales y técnicos pasan de una esfera a otra, filman comerciales o películas, ficción o documental y van "polinizando" con sus experiencias todas las áreas de producción audiovisual, como sucede con la televisión, el cine publicitario, los productos audiovisuales en general. Esto sucede especialmente con dos áreas: la de Fotografía y la de Dirección de Arte, que por sus características de ser equipos de permanente ocupación en proyectos diferentes, tienen la posibilidad de construir experiencias estéticas de diferentes características, en un tiempo muy breve, en ámbitos muy diferentes. El trasvase continuo entre estos ámbitos no sólo es de experiencias técnicas y estéticas, sino de una manera de abordar cualquier proyecto mediante una metodología de trabajo común.

El rol de la Dirección de Arte en el cine del S XXI, los medios audiovisuales y las nuevas tecnologías

El cine de este siglo encuentra un panorama heterogéneo en cuanto a estéticas, de intercambio de influencias y desaparición de fronteras entre cinematografías, géneros y formatos. En este contexto donde lo único predecible y constante son el cambio y la incertidumbre, la cultura de la imagen toma un rol preponderante desde mediados del siglo pasado en detrimento de las formas de comunicación oral y escrita. Esto significa que hay muchas más imágenes en nuestra vida cotidiana que hace cincuenta años, que la comunicación de las imágenes en movimiento reemplaza a las otras formas de comunicar e informar, y que nuestra postura como consumidores nos vuelve mucho más sensibles y exigentes respecto a su calidad. El diseño toma el lugar que tradicionalmente tuvieron otras actividades en nuestra cultura, como la elaboración artesanal de objetos de uso, el rol de la pintura y la escultura dentro de la vida cotidiana y la forma de la ropa que llevamos. A una sociedad que "estetiza" la elaboración de la experiencia, corresponde una visualidad capaz de expresar y hacernos accesibles lo que antes confiamos casi exclusivamente a la importancia de la palabra oral primero y escrita después.

La Dirección de Arte encuentra en estas circunstancias un rol más importante que en las cinematografías anteriores, por la exigencia en cuanto al papel de lo visual en la narrativa y en la realización de las intenciones expresivas de cada proyecto. A esta importancia corresponde el desarrollo de proyectos de ficción que involucran no sólo los recursos físicos tradicionales sino un mayor papel de los efectos especiales. No es nuevo el rol de los efectos especiales para aliviar a la producción de la construcción de escenografías monumentales o de la presencia de multitud de extras para ciertas escenas, pero si es nuevo el acceso a las tecnologías necesarias para que estos recursos puedan ser usados por producciones de pequeño presupuesto. Los recursos de construcción y efectos digitales han venido a ampliar nuestro campo de diseño, permitiéndonos explorar géneros antes imposibles y también producir animaciones y videojuegos capaces de insertarse en pie de igualdad en el medio internacional. Este campo de la escenografía virtual o generada por computadora es un territorio de trabajo nuevo que se abre a los Directores de Arte, a la vez que multiplica los recursos y permite experiencias estéticas antes impensables. El desafío es aprender a sacarle partido a estas técnicas, lo que no significa linealmente ser operadores de estos programas, pero si conocer profundamente sus posibilidades y las lógicas de producción propias de estas áreas.

Perspectivas de la disciplina

La ruptura más importante con los viejos métodos de producción es la posibilidad de acceso a los medios de captura y montaje, en especial por el desarrollo del video. El video posibilitó también nuevas formas de consumir cine a través primero de los reproductores analógicos de uso doméstico, la aparición de "videoclubes" y luego de 
otros formatos y reproductores, con el acceso online a materiales que pueden visionarse a muy bajo costo o de forma gratuita. Las cámaras de video de uso amateur se multiplicaron, se volvieron más pequeñas y livianas, y finalmente se insertaron en los celulares y otros dispositivos móviles de consumo masivo y precios accesibles. Eso convierte hoy a cualquier individuo en un potencial creador de imágenes y mensajes audiovisuales, con acceso a distribuirlos al margen del sistema tradicional. También se universaliza el acceso a materiales audiovisuales en tiempo real, a la hora y momento que quiera el espectador desde su casa o desde cualquier punto donde esté con un dispositivo capaz conectarse. No sólo podemos ahora ver tantas veces como queramos una película, sino que tenemos la forma de pausarla y congelar la imagen, es decir: de explorar con nuestros tiempos propios la obra, atomizada en encuadres que no fueron diseñados para ser vistos ni analizados cuadro a cuadro. O tenemos la posibilidad de "navegar" la obra, salteando secuencias y realizando una experiencia perceptual totalmente diferente a la propuesta por el director. También, y esto es quizás lo más interesante, es posible intervenir las obras de otros, con recursos de uso muy simple, y crear versiones nuevas mediante el "remix" de imágenes y sonidos.

Se instala entonces la polémica sobre si estamos frente a la desaparición de ese mundo profesional, que basaba su poder sobre las especificidades técnicas en el manejo de equipos complejos y del material fílmico. Si es así, estamos también asistiendo a la desaparición de las viejas técnicas de la dirección de actores, que se basaban en el ensayo previo para ahorrar el costoso material fílmico. Con la caída de esta barrera, el abaratamiento y simplificación de los equipos y programas informáticos trae una segunda tanda de posibilidades: la de generar materiales audiovisuales y distribuirlos en internet, de forma gratuita y evitando el control de las formas tradicionales de distribución y exhibición.

Posiblemente, así como asistimos a la sorpresiva desaparición del material fílmico y de los laboratorios, estemos demasiado adentro de la carrera tecnológica como para poder evaluar su real impacto en el lenguaje audiovisual del futuro. Desde el punto de vista del fin del cine, como dice Alexander Kluge, es posible que asistamos a la desaparición de las formas de hacer y de ver cine tal como lo conocíamos desde sus comienzos, que cambien dramáticamente los formatos, pero así como el cine precede al cine, posiblemente lo sobreviva. Si el cine es considerado en su más amplia acepción, como el conjunto de procesos de elaboración de experiencias y su visualización, por ejemplo como ocurre en la lectura de una ficción, donde la literatura estimula la generación de imágenes que representan y ponen en escena una historia, el cine es anterior al cine tal como lo conocemos. E cine de las cámaras, de los proyectores, de las salas donde la experiencia es colectiva tal vez se transforme totalmente, pero eso no significa su muerte, porque los mismos procesos que lo sustentan, como la necesidad de contar y de conocer historias que nos acerquen a nosotros mismos, simplemente tomará otras formas.

Así como el hecho de que la existencia de lápices y su accesibilidad no implica que todo el que sea capaz de dibujar con ellos sea un diseñador o tenga la capacidad de comunicarse por medio de las formas gráficas, o de generar arte, es posible que el acceso a los medios técnicos facilite el acceso a más potenciales cineastas, pero no nos asegura nada respecto a la calidad de sus obras. Lo importante sigue estando en otro lado: en el artista capaz de usar estos medios técnicos o elegir entre todas las posibilidades aquellos que le permitan hacer coincidir sus intenciones con los resultados.

La formación de Directores de Arte en contexto académico en la región.

La redención del robot 
En la sociedad, los intereses de los individuos están entrelazados y no pueden separarse. Los hombres deben aprender a ayudarse mutuamente. En otras palabras, la ayuda mutua es uno de los factores de la felicidad individual, y estas dos facetas de la existencia del hombre son interdependientes.

La educación es el proceso por el cual se ha de llegar al armónico equilibrio de ambas. (Herbert Read)

Desde el principio de la historia del cine los Directores de Arte han venido de áreas afines, como la arquitectura, la pintura, el diseño, el teatro y también de formaciones polivalentes en realización de cine. La práctica y la experiencia junto a profesionales más experimentados constituyo durante casi cien años la forma de iniciarse en la profesión y de adquirir los conocimientos necesarios para el desempeño del rol, en un sistema casi medieval de trasmisión de los conocimientos de maestro a aprendiz de manera asistemática e informal. Como el rol involucra aspectos muy amplios tanto artísticos, como técnicos, vinculados a la producción y a la capacidad de generar respuestas originales a problemas conceptuales y prácticos pero a la vez se requiere una cierta experiencia en el manejo de materiales y en la gestión de proyectos y equipos de trabajo, los perfiles de los Directores de Arte son variados en cuanto a su formación académica y todos exigen un complemento de capacitación en las áreas en las que no han tenido formación.

La formación académica de los Directores de Arte se inicia a nivel universitario en EEUU recién en 1995, y hasta el presente son pocos los centros de formación terciarios o universitarios que ofrecen formación de grado, como especialidad, en Dirección de Arte. En la mayoría de los centros de formación latinoamericanos la Dirección de Arte es una materia presente a lo largo de la carrera de grado, pero con una cantidad de horas clase menor a otras materias consideradas básicas, como fotografía o sonido. La especialización en Dirección de Arte como tal se desarrolla a nivel de posgrado en la EICTV (Diploma de $320 \mathrm{hs}$, formato intensivo) y en la FUC (Posgrado en Dirección de Arte, Nivel Maestría), además de otras propuestas de institutos y escuelas sin reconocimiento oficial, a los que se suman gran cantidad de talleres, cursos breves y seminarios cuya carga horaria oscila entre las 20 y las 80 horas y que operan sin marco institucional. En Argentina la carrera de Dirección de Arte se instala en 2013, en la ENERC, Escuela dependiente del Instituto del Cine, como carrera de grado luego de una formación polivalente, con talleres propios y bajo la dirección de la D. De Arte Margarita Jusid..

Los desafíos conceptuales y prácticos de la formación de directores de arte en un contexto académico

El hecho de que la materia de una ciencia este organizado demuestra que ha estado sometido a la inteligencia, que ha sido metodizado (...). El método significa aquella organización de la materia de estudio que la hace más eficaz en el uso. (John Dewey)

La sistematización de los conocimientos y experiencias en la Dirección de Arte es un terreno poco transitado, incluso a nivel internacional. La literatura específica es mayoritariamente en forma de testimonios de profesionales que describen algunos casos de trabajo, de manuales que explican el rol, la organización del departamento y algunos aspectos técnicos relacionados con la construcción de escenografías y el manejo de presupuestos, el uso del color luz y las ópticas. Falta reflexión teórica que sistematice estas experiencias y trascienda el anecdotario de mero interés testimonial sobre procesos de trabajo específicos. Lo que se encuentra publicado en general tiende a mostrar, no a sistematizar el conocimiento ni a plantear problemas conceptuales. Por eso, es necesario acudir a fuentes variadas, donde sí se ha dado una reflexión profunda sobre los fenómenos visuales generados por el cine o por las imágenes en general, su incidencia en la cultura 
contemporánea y la manera en la que los diferentes formatos de producción responden a concepciones filosóficas, ideológicas, económicas y políticas de un determinado contexto. Hay una tarea necesaria de adaptación de los esquemas de concebir y gestionar los proyectos desde un medio profesional desarrollado, regulado y con una fuerte tradición a los desafíos que presentan las cinematografías contemporáneas latinoamericanas, con presupuestos mucho menores y esquemas de trabajo no totalmente regulados. Los esquemas de producción con mayor tradición tienen la ventaja de haber logrado condiciones de trabajo sustentables, con sistemas de categorización profesional y regulaciones protectoras de los derechos sociales de los trabajadores. Los esquemas más nuevos, como el nuestro, están basados en una mística voluntarista que fue necesaria para impulsar el cine en un país que no tenía ninguna experiencia continua ni regular de producirlo, que entra en conflicto con las necesidades de los profesionales cuando estos se dedican exclusivamente a trabajar y vivir de y en el medio de producción audiovisual: desregulación del trabajo, prácticas riesgosas o insalubres, falta de oportunidades para la formación continua y la actualización de conocimientos.

Cuando planteamos contenidos y actividades en nuestros planes de trabajo en realidad no sabemos para qué futuro estamos formando, cuánto de lo que hoy se considera necesario incorporar a la práctica será parte de su futuro ejercicio de la disciplina. Ampliar los abordajes teóricos entrando en contacto con aportes que vienen desde el cine, pero también desde la estética, la filosofía y la ciencia es una forma de dar un anclaje más generoso a las preguntas que debe formularse un Director de Arte cuando aborda un proyecto nuevo, pero también cuando está en medio de un rodaje y debe tomar una decisión rápida, o cuando elabora una experiencia práctica.

Por eso, más que trasmitir contenidos es necesario fomentar la curiosidad y la investigación, y más que exigir resultados, tenemos que hacer que los estudiantes experimenten con placer los procesos de elaboración creativa, tomen riesgos, exploren alternativas y sobre todo, entiendan que en el audiovisual es fundamental el trabajo en equipo. Gestionar los aportes creativos y la productividad de un equipo es tanto o más importante que tener una buena idea. Las mejores ideas en el audiovisual necesitan de los colegas involucrados, del contexto social y de una relación constructiva entre todas las partes involucradas para concretarse y trascender del papel a la pantalla.

Desde el punto de vista conceptual un director de arte necesita una sólida formación estética que integre diferentes lenguajes y técnicas, y que le permita abordar cualquier proyecto con las herramientas necesarias para investigar, establecer hipótesis, relacionarlo con sus experiencias pasadas y establecer un diálogo fructífero con las experiencias cercanas y también las del corpus que constituyen las películas filmadas antes, las obras y artistas que lo precedieron, con las fuentes lejanas y cercanas que pueden alimentarlo y con sensibilidad para reconocer en el contexto periférico de su momento cultural , aquellas manifestaciones que aún no forman parte de la cultura oficial. El diálogo no debe nunca ser sólo con lo inmediato y de 'fácil acceso: es necesario experimentar las dificultades de la investigación, no conformarse con las primeras respuestas y ampliar todo lo posible los puntos de vista, evitando el reduccionismo y las recetas. Si la construcción de un mundo visual fuera posible aplicando fórmulas sería ciencia, y es ante todo arte: exige respuestas capaces de conmover sin caer en las soluciones fáciles. Un director de arte necesita también experiencias prácticas: necesita probar sus hipótesis, construir, pintar, probar materiales, experimentar el espacio a escala real y tener la experiencia directa de cómo reaccionan juntos ciertas texturas y colores, para poder ejercitar su capacidad de elegir y discriminar entre lo que funciona y lo que no aporta nada, o evaluar en términos de tiempos y costos un recurso. En términos ideales, las experiencias deberían desarrollarse en una diversidad de escenarios: en el taller y en experiencias transversales 
que pongan en relación de trabajo a los diferentes roles, ejercidos entre estudiantes, pero también las experiencias de trabajo en el medio profesional, que posibilite el intercambio intergeneracional. Las experiencias transversales tienen la ventaja de ser experiencias siempre entre iguales, que desde diferentes roles llevan adelante un proyecto, pero también tienen limitantes de tiempo y recursos que deberían ser compensados con instancias de tipo laboratorio, donde experimentar específicamente sus hipótesis antes de llevarlas al rodaje, sin las presiones de un resultado exitoso obtenido dentro del tiempo de rodaje. Como los pilotos, los técnicos del audiovisual acumulamos experiencias en horas de vuelo, y es fundamental que un alumno haya tenido las necesarias en el contexto académico, para incorporar el hábito de la experiencia seguida de reflexión y aprendizaje. El ámbito de la clase es un campo liberado de tensiones que sí afectan al campo de la práctica profesional, que se puede ver beneficiado y modificado por las formas de trabajo que devienen de la formación activa. El campo del trabajo no tiene por qué ser hostil, insalubre ni autoritario. Puede ser un espacio tan respetuoso, alegre y estimulante al desarrollo integral como un espacio educativo, siempre que sea vivido como el lugar que hemos elegido para concretar nuestros proyectos creativos, en base a la experiencia-aprendizaje, no a la repetición rutinaria que desgasta y empobrece.

La aplicación de estrategias y técnicas didácticas de la enseñanza activa de Dirección de Arte, se beneficia de la aplicación al estudio de casos, la resolución de problemas y la enseñanza por proyectos.

1. El estudio de casos se realiza mediante el análisis de películas, donde se explora en los recursos estéticos utilizados, vinculando el diseño con sus relaciones de pertenencia o confrontación con modelos estéticos devenidos de la historia de las manifestaciones artísticas, consideradas en su más amplia acepción, tanto en la historia del arte como en las señales que marcan la vida cotidiana. Estas manifestaciones se contextualizan dentro del contexto histórico en el que se desenvuelve la obra, para un abordaje comprensivo de como la cultura material se relaciona con los aspectos tecnológicos, de relación con los modelos históricos del pasado, con los contactos con las culturas lejanas y la incorporación de aportes de lo que podemos llamar la "periferia" cultural. Se analiza desde el punto de vista perceptual los recursos formales puestos en juego y su relación con la comunicación de contenidos objetivos (época, lugar, situación del personaje dentro de su sociedad) y los aportes expresivos (que siente el protagonista al atravesar las circunstancias de la historia). El estudio de casos es útil también para analizar las imágenes como resultado de una construcción en "capas" o "layers", donde la información se dirige a un público masivo, que interpreta y comprende según su nivel de formación e información previa sobre lo que se muestra. La construcción en capas de significación es un recurso que permite a los creadores asegurar la relación perceptual ( común a todos los espectadores de una manera genérica en tanto la base fisiológica es el común denominador), introducir datos que son accesibles a la mayoría de los espectadores ( en tanto partícipes de la cultura) y proponer lecturas más finas y específicas, donde se profundiza la intención a niveles que exigen del espectador un conocimiento más "experto" para apreciar los matices de intención.

2. El planteo de "problemas" creativos, de una manera escalonada: mirarse a sí mismos, mirar al otro y explorar qué elementos visuales pueden ser puestos en juego para construir una identidad visual específica, capaz de comunicar y también de sensibilizar. El planteo de consignas se puede realizar también a dos niveles: planteo de consignas que los pongan en contacto con la realidad de la producción práctica y otras que despejen estas variables y les permitan diseñar con prescindencia de los límites de la carencia de recursos. El trabajo en forma individual, en duplas y en equipos que involucran a todos los estudiantes, permite experimentar las diferentes formas de intercambio creativo y organización del trabajo por objetivos concretos. Los problemas generados como territorio propio de la disciplina ayudan a explorar formas de planificar y llevar adelante los proyectos, con 
la vivencia integradora de los aportes teóricos de otras materias, como base para la investigación, la selección de lo pertinente, la elaboración de un diseño y los documentos que lo comunican, que se unen en lo que llamamos la "carpeta de arte", un documento único que expone los resultados de todo el proceso.

3. El desarrollo de proyectos. Los proyectos pueden presentarse en dos formatos básicos: los propios del taller de Dirección de Arte y los que se realizan transversalmente con las otras áreas. En los primeros se trabaja en un contexto ideal de producción, para poner foco en los procesos creativos y en las propuestas estéticas. Los ejercicios de rodaje transversales colocan a los estudiantes en una experiencia directa con los intercambios creativos en grupo, la dinámica de trabajo y la gestión de un proyecto interdependiente del trabajo de los otros y de las condiciones concretas del medio donde se desarrolla. Tienen como resultado una obra, que ha pasado por todo el proceso: desde la experimentación de la hipótesis en el pre producción, a la puesta en realidad durante el rodaje y los procesos de montaje y post producción de imagen y sonido. Esta concreción es un material valiosísimo para el análisis, la autoevaluación y la devolución individual y grupal.

Desafíos en la formación de los directores de arte en el contexto regional

En un contexto regional, el primer desafío refiere a la adecuación de las propuestas de formación a las necesidades del medio audiovisual, teniendo en cuenta que el medio que hemos desarrollado en las décadas anteriores ha generado prácticas que respondían a lógicas de producción no profesionalizadas, voluntaristas, inspiradas en el ámbito de la producción de publicidad en los modelos industriales tradicionales. Nos encontramos entonces con un medio profesional resistente a verse a si mismo como un sector productivo que debe organizarse de manera sustentable, ya que las prácticas del trabajo como evento no regular no debe continuarse en la actualidad, porque no condice con las circunstancias actuales de la producción ni con las regulaciones internacionales ni nacionales. Concebirse a sí mismos como trabajadores es problemático en general para los profesionales del audiovisual, por varias razones que tienen que ver con la naturaleza misma del trabajo y su inserción permanente como sector productivo. En especial, para los directores y equipos de arte, la naturaleza "artística" del oficio se confunde con otras prácticas artísticas no remuneradas, por lo que se naturaliza la participación sin honorarios en proyectos de corte independiente, o las condiciones de remuneración por debajo de los honorarios usuales, en los casos de los que ingresan al medio, situación que se prolonga hasta varios proyectos con una misma casa productora. Estas practicas, que pueden ser parte de una forma de hacer posibles los proyectos "independientes" del cine (los que ruedan sin apoyo financiero), se extienden a el sector de la publicidad y de la producción televisa, por lo que nos encontramos con lo peor de los dos mundos: condiciones de trabajo sin regulación y exigencias con estándares de cine industrial. El cine en su formato industrial, si bien en crisis, desarrolló junto con la producción "en serie", poco estimulante desde el punto de vista artístico, o las relaciones verticales de autoridad, una serie de medidas de protección para sus trabajadores que contribuían a hacer de la carrera profesional un recorrido sustentable en términos de salud, integración intergeneracional, condiciones de remuneración y protección social. Es importante que en la formación de los futuros diseñadores estos elementos que hacen a la concepción de la carrera sean motivo de análisis y reflexión. No hay un solo modelo posible, sino varios: el modelo flexible, con varios roles en una sola persona condice con un ejercicio irregular de la profesión, dedicado a aquellos proyectos de corte más "artístico" o experimental, que tienen su lógica de financiamiento en general fuera del circuito de la producción audiovisual y dentro de los fondos destinados a las artes visuales. El otro modelo es el del profesional que puede, en especial en nuestra región, trabajar tanto en el cine, como el cine publicitario o la televisión, en un modelo de trabajador freelance, y circunstancialmente integrarse a proyectos de corte experimental. En cualquiera de los 
casos, el modelo debería tender a generar un medio de trabajo ajustado a derecho, donde el acceso y la integración al medio audiovisual no se restrinja por razones de origen social, edad o género, y donde sea posible que un diseñador tenga una carrera laboralmente extensa, de manera que las capacidades y experiencias de los más jóvenes y los mayores estén en relación directa y enriquecedora.

El segundo desafío es especifico de la disciplina, pero íntimamente ligado a los aspectos ideológicos que subyacen a la construcción de la identidad visual de nuestras cinematografías y productos audiovisuales. En la medida en que se desarrollen los contextos académicos de la disciplina y se dediquen recursos para establecer espacios de laboratorio, se hará posible profesionalizarla y derribar las barreras que limitan su acceso a sectores sociales más alejados, geográfica y económicamente, de los centros de producción. Esto es importante para la construcción de productos que enriquezcan con otros tonos, contenidos y estéticas la producción audiovisual de identidad fuertemente centralizada en la estética, los temas y tonos que priman en nuestro cine con una mirada predominantemente urbana y de clase social media, que por sensible que sea, se acerca a otros medios y problemáticas desde su propia circunstancia vital. La construcción de identidad visual no quiere decir "costumbrismo" necesariamente, ni imposición de elementos tradicionalmente asociados con lo popular, sino también el reconocimiento de la rica diversidad de aportes y contradicciones que nos atañen por nuestra experiencia cultural. El diseño de arte puede acercarse al problema de la identidad de varias maneras, como lo demuestra el cine de la era dorada de Hollywood: a través del apunte grueso que reduce los elementos visuales propios de una cultura o los adapta para que sirvan de sustento exótico a una estrella o una historia. El reduccionismo típico de los años cuarenta aun subyace en producciones actuales, porque es una formula perezosa pero efectiva en audiencias masivas, pero en su mayor parte queda limitado a las producciones de cine comercial de géneros como el de acción, donde el reduccionismo en lo visual acompaña a otros conceptos ideológicos igualmente dicotómicos. La otra manera de acercarse a la representación de universos lejanos en el tiempo o el espacio es la que se exige a sí misma investigar profundamente las claves visuales de ese contexto particular, estructurando un discurso visual que tome las claves formales de esa realidad y encuentre los matices y tonos diferentes que ayuden a construir personajes y entornos con identidades propias y diferenciadas dentro del contexto general. La investigación y selección de los elementos significantes al proyecto de arte son los pasos fundamentales de abordaje de cualquier proyecto, y sus aportes no limitan la creatividad de los diseñadores, sino que multiplican los estímulos que pueden volverse recursos de representación o expresión.

El tercer desafío tiene que ver con comprender y valorizar tanto la vertiente teórica como práctica de la Dirección de Arte. El diseñador que puede enriquecer su sensibilidad con múltiples posibilidades de experimentar y convertir el medio académico en un campo de prueba de técnicas, recursos expresivos y experiencias de realización y producción en el ámbito controlado del medio académico llega a la vida profesional con recursos que acortan el camino del ensayo y el error, con los costos personales y productivos que implican. La ausencia de estos espacios limita la formación al reducirla a instancias teóricas que no encuentran su correlato necesario en la puesta en práctica de los contenidos y propuestas. La generación de estos laboratorios o talleres es un debe en la mayor parte de nuestros centros educativos, que reducen la formación a la producción de vestuario o ambientación que los estudiantes puedan encontrar ya realizados, sin tener la posibilidad de alterar su apariencia con efectos de envejecimiento o deterioro por el uso, que sí requieren las historias en las que trabajan. Dentro de la vertiente práctica se incluye el manejo de herramientas digitales de diseño, en especial el conocimiento profundo de las de generación de espacios virtuales, el diseño gráfico, los recursos de post producción de la imagen. Como en el caso de las técnicas de construcción y efectos tradicionales, no se trata de 
que el director de arte acapare estos roles, sino que conozca profundamente sus posibilidades y pueda diseñar en función a todos los recursos disponibles.

El cuarto desafío de la formación de directores de arte que puedan pivotar entre las exigencias de la producción ajustada a patrones internacionales de calidad y las exigencias de rodar proyectos con bajo presupuesto es quizás el más interesante a nivel teórico, porque nos lleva directamente al problema de instalar metodologías de conceptualización, diseño y producción que sean válidas en todo el abanico que se extiende entre estos dos tipos de proyectos. Si bien los recursos disponibles de tiempo, materiales, humanos pueden no ser los ideales, la queja y el abandono de la intencionalidad estética no es la respuesta adecuada. Lo importante es desarrollar estrategias de diseño y de producción que no pierdan de vista esa intencionalidad estética, aun cuando deba ser producida en condiciones difíciles. El criterio de pertinencia es una medida que puede ejercerse en la selección de los elementos de arte con rapidez y dentro de los recursos disponibles si la base conceptual (investigación, documentación, diseño) están firmes, y es la que nos guía cuando tenemos una cantidad limitada de opciones para elegir, todas ellas posibles, pero no todas pertinentes a la intencionalidad estética. Puedo tener dos sweaters de la talla del actor y ni uno más, pero uno de ellos resultará relativamente más adecuado que el otro, porque sus cualidades formales se ajustan a lo que he definido como la gama de colores, texturas y formas del personaje, a los tonos y matices que lo separan por contraste (o por lo contrario, lo pegan) al fondo de la imagen. Elegir los elementos que realizan una propuesta depende de la cantidad de opciones que nos permitan los recursos disponibles, pero aun dentro de recursos abundantes, es fundamental que los criterios estéticos se establezcan de antemano, de manera que este encuentro entre las intenciones y su concreción realice la propuesta general que hemos definido centrada en las cualidades puramente visuales de los elementos, independientemente de factores definidos por las circunstancias de la producción. Quizás esto sea lo más difícil de gestionar en medio del desarrollo del rodaje o de preproducciones demasiado breves, por lo que la etapa de diseño adquiere una importancia aun mayor: cuanto más firme esté el diseño, más internalizado como la dirección hacia la que todo el equipo debe avanzar, menos vulnerables estaremos a perder el control de los elementos que entran en cuadro, de ignorar su peso visual o cultural por priorizar por ejemplo, su pertenencia a un género de objetos que cumplen otros cometidos, como responder a la categoría genérica de "cuchillo capaz de matar". Puedo tener una amplia gama de posibilidades de cuchillos que cumplan por su tamaño y materiales esta doble función de herramienta para trozar comida y arma blanca, pero el tamaño, los materiales de los que está hecho, el formato (de mesa, de cocina, de uso doméstico, de uso profesional), los elementos decorativos o de diseño que definen su antigüedad, lugar de origen y valor, abren variedad de posibilidades. No es lo mismo un arma para cacería que un cuchillo de mesa o uno de cocina, y aun dentro de una de estas categorías, digamos, de mesa, la gama de posibles opciones es amplia. Puede ser un cuchillo barato, de sierra y mango de madera, comprado en un supermercado, o puede ser un cuchillo antiguo, que luzca como plata, con más peso que el primero y el mango ornamentado. En uno y otro caso, las armas "narran" cosas diferentes sobre el entorno objetivo y las circunstancias emocionales involucradas: el cuchillo barato habla de una situación diaria, en medio de la cotidianeidad doméstica, mientras que un cuchillo más valioso, de los que se reservan para ocasiones especiales, hablará de un evento especial, como una cena formal. Aun si la situación se desenvuelve en un mismo espacio, supongamos la casa de una pareja de clase media, donde uno y otro tipo de cuchillos son posibles, el uso de uno u otro tiene por un lado diferentes elementos formales para ofrecer a un primer plano, pero también diferentes capacidades de sugerir o evocar las circunstancias de su uso. Ambos cuchillos posibles no son intercambiables. Lo mismo sucede con los elementos de vestuario, en cuanto a su capacidad de comunicar datos sobre los personajes que dependen de sus características formales y de las asociaciones que 
puede generar. No es lo mismo un paraguas masculino, negro y simple para ser usado por un personaje femenino que si este elemento tiene un diseño original, que lo separa y lo hace significativo en un conjunto dominado por formas más comunes y simples, lo que implica para el diseño del personaje un aporte económico en términos narrativos.

Se trata en síntesis, de enfocarse en lo esencial del diseño de arte: la capacidad de las formas de generar información, de narrar, de expresar. Y cada proyecto, independientemente de su presupuesto, género y formato, necesita del diseño de arte a la hora de hacer coincidir las intenciones estéticas de la realización con lo que aparece en la imagen.

Posiblemente estemos en el mejor momento para constituir un cuerpo y estrategias de formación propias, que superen las barreras ideológicas que en el pasado asimilaron el diseño de arte con la decoración, la producción en formato industrial y los fines comerciales relacionados con el consumo masivo de estéticas hegemónicas. En cuanto podamos despejar estas barreras invisibles, y hacer visibles los desafíos reales, como la necesidad de propiciar diseño de calidad en todos los formatos y espacios de creación cinematográfica, aun los más periféricos, los elementos ideológicos que subyacen en la enseñanza activa y la producción colaborativa nos acercarán a un formato de la disciplina más ajustado a las demandas del cine contemporáneo.

Bibliografía

Aumont, J. (1992). La Imagen. Barcelona: Ed. Paidós. . (1997). El ojo interminable. Barcelona: Ed. Paidós.

Bazin, A. (2008). Qué es el cine. Madrid: Ed. Rialp SA.

Bonitzer, P. (2007). Desencuadres, Cine y pintura. Santiago Arcos Editor.

Chateau, D. (2010). Estética del Cine. La Marca Editora.

Ettedgui, P. (2002). Diseñadores de producción, Dirección de Arte. Ed. Océano.

Jimenez, J. (2004). Teoría del arte. Madrid: Alianza Editorial.

Gardies, R. (2014). Comprender el cine y las imágenes. La Marca Editora.

Landis, D. (2014). Diseñadores de vestuario. Ed. Blume.

Lo Brutto, V. (2002). Guide to Production Design. Ed. Paperback.

Ranciere, J. (2012). El reparto de lo sensible, estética y política. Ed. Prometeo.

Rizzo, M. (2005). The Art Direction Handbook for Film. Ed. Focal Press.

Tashiro, C. S. (1998). Pretty Pictures: Production Design and the History Film. Ed. University of Texas. 
Ward, P. (1994). What an Art Director Does: An Introduction to Motion Picture Production Design. Ed. Paperback.

Whitlock. C. (2010). Designs on Film: A Century of Hollywood Art Direction Hardcover. It Books.

Yoel, G. (comp.) (2004). Pensar el cine 2.- Cuerpos, temporalidad y nuevas tecnologías. Ed. Corregidor.

Abstract: Present in the cinema from Meliés, the physical sustenance of the cinematographic image involves multiple knowledges, capacities and projects and production experiences that have not always been credited in the works. His academic approach at university level is just twenty years long, and we are talking about a discipline that is born next to the cinema. Many factors, prejudices and ideological aspects now find an opportunity to revert from the field of training spectators and designers, thanks to the need to systematize and integrate this knowledge and experience of practice with the conceptual approaches that give them meaning It is necessary to elaborate contents and pedagogical strategies that respond to the need to train designers capable of adding value to audiovisual projects.

Key words: cinema - design - art - space - image.

Resumo: Presente no cinema desde Meliés, o sustento físico da imagem cinematográfica envolve múltiplos saberes, capacidades e experiências projetuais e de produção que não sempre foram acreditadas nas obras. Sua abordagem acadêmica a nível universitário tem vinte anos, mas é uma disciplina que nasceu junto ao cinema. Múltiplos fatores, prejuízos e aspectos ideológicos encontram hoje uma oportunidade de se reverter desde o âmbito da formação e espectadores e de designers, devido à necessidade de sistematizar e integrar estes conhecimentos e experiências da prática com as abordagens conceituais que lhes dão sentido. É necessário então elaborar conteúdos e estratégias pedagógicas que respondam à necessidade de formar designers capazes de aportar valor aos projetos audiovisuais.

Palavras chave: cinema - design - arte - espaço - imagem

La Dirección de Arte en el cine, desafíos disciplinares y pedagógicos fue publicado de la página 39 a página61 en Cuadernos del Centro de Estudios de Diseño y Comunicación № 67 